\title{
Kualitas Gaharu Aquilaria sp. dengan Pemberian Bioinokulan Fermentasi Batang Pisang yang Terkena Penyakit Layu Fusarium
}

\author{
(Quality of Aquilaria sp. Agarwood by Giving Bioinoculants Fermented Banana Stems Affected by \\ Fusarium Wilt Disease)
}

\author{
Silvester Selno*, Zulfa Zakiah, Rikhsan Kurniatuhadi \\ Program Studi Biologi, Fakultas MIPA, Universitas Tanjungpura, \\ Jl. Prof. Dr. H. Hadari Nawawi, Pontianak, \\ *Email: silvesterselno@student.untan.ac.id
}

(Article History: Received February 1, 2021; Revised March 8, 2021; Accepted April 7, 2021)

\begin{abstract}
ABSTRAK
Upaya produksi gaharu budidaya umumnya menggunakan inokulan dari jenis Fusarium sp., namun mahalnya inokulan biakan murni menjadi faktor pembatas untuk produksi gaharu budidaya. Bioinokulan dapat menjadi solusi bagi petani gaharu karena dibuat dari bahan yang mengandung mikroorganisme patogen dan tidak membutuhkan proses pembiakan murni. Penelitian ini bertujuan untuk mengidentifikasi jenis-jenis mikroorganisme dan konsentrasi bioinokulan yang tepat digunakan untuk menghasilkan kualitas gaharu yang baik serta mengetahui kualitas gaharu yang dihasilkan dengan menggunakan bioinokulan dari fermentasi batang pisang yang terkena penyakit layu fusarium. Metode penelitian lapangan dengan melakukan inokulasi bioinokulan dari fermentasi batang pisang yang terkena penyakit layu fusarium pada pohon Aquilaria sp. Setiap konsentrasi diinokulasikan pada pohon yang berbeda. Pada ketinggian $30 \mathrm{~cm}$ dari permukaan tanah, pohon dibuat lubang sebanyak 5 buah secara vertikal dengan menggunakan bor dengan jarak antar lubang $50 \mathrm{~cm}$. Inokulan diinokulasikan melalui lubang yang telah dibuat dengan metode infus. Hasil penelitian diperoleh tiga jenis mikroorganisme yang terdapat pada bioinokulan yaitu kelompok genus Aspergillus, Fusarium dan Saccharomyces. Perlakuan dengan konsentrasi bioinokulan $140 \mathrm{ml}$ memberikan hasil yang terbaik terhadap bobot kayu gaharu, warna, aroma dan kadar resin gaharu yang dihasilkan. Berdasarkan penelitian ini dapat disimpulkan bahwa kualitas gaharu yang dihasilkan setelah 4 bulan inokulasi menghasilkan mutu gaharu kelas kemedangan.

Kata Kunci: Aquilaria sp., Bioinokulan, Fusarium sp., Gaharu, Inokulasi
\end{abstract}

\begin{abstract}
Efforts to produce cultivated agarwood generally use inoculants of the type Fusarium sp. however the high cost of pure culture inoculants is a limiting factor for cultivated agarwood production. Bioinoculants can be a solution for agarwood farmers because they are made from materials containing pathogenic microorganisms and do not require a pure breeding process. The research aims to determine the kind of microorganisms and the proper concentration of bioinoculants to produce good quality agarwood and determine the quality of aloes produced by using bioinoculants from fermented banana stem affected by fusarium wilt disease. The method of field research was by conducting inoculation of bioinoculants from the fermentation of banana stems affected by fusarium wilt on Aquilaria sp. Each concentration was inoculated on a different tree. At a height of $30 \mathrm{~cm}$ from the ground, 5 holes are made vertically using a drill with a distance of $50 \mathrm{~cm}$ between the holes. The inoculant is inoculated through the hole that has been made by the infusion method. The results showed that there were three types of microorganisms found in bioinoculants, namely the Aspergillus, Fusarium and Saccharomyces genus groups. Treatment with a concentration of $140 \mathrm{ml}$ of bioinoculant gave the best results on the weight of agarwood, color, aroma and content of the resulting agarwood resin. Based on this research, it can be concluded that the quality of aloes produced after 4 months of inoculation resulted in the quality of agarwood in the kemedangan class.
\end{abstract}

Keywords: Agarwood, Aquilaria sp., Bioinoculants, Fusarium sp., Inoculation 


\section{PENDAHULUAN}

Gaharu ialah kayu yang berwarna kehitaman dan mengandung resin khas yang dihasilkan oleh spesies pohon dari genus Aquilaria dan merupakan salah satu hasil hutan bukan kayu (HHBK) yang memiliki nilai ekonomi yang tinggi (Siran dan Turjaman 2010). Gaharu biasa diperdagangkan untuk keperluan industri parfum, kosmetik, kerajinan tangan, dupa atau hio, obat-obatan dan juga acara ritual keagamaan. Banyaknya kegunaan gaharu membuat meningkatnya permintaan pasar terhadap gaharu dan menyebabkan proses pencarian gaharu di alam meningkat sehingga sulit untuk dikendalikan. Salah satu upaya pemerintah untuk menanggulangi perburuan liar gaharu dengan melakukan pembatasan ekspor dengan kuota untuk gaharu alam. Untuk menanggulangi hal tersebut maka para petani gaharu mulai untuk membudidayakan gaharu, karena untuk gaharu budidaya tidak dikenakan pembatasan kuota ekspor. (Purnomo dan Turjaman 2011).

Upaya peningkatan produksi gubal gaharu telah dilakukan oleh beberapa peneliti, seperti yang telah dilakukan oleh Santoso et al. (2011a) dan Santoso et al. (2011b) yang menghasilkan gaharu dengan mutu kemedangan $\mathrm{C}$ pada usia 3 bulan inokulasi. Vantompan et al. (2015) membandingkan inokulan Fusarium sp. dengan metode infus dan metode injeksi pada Aquilaria malaccensis dimana metode infus secara morfologi menunjukan adanya perubahan warna kayu yang sangat signifikan dari putih menjadi hitam jika dibandingkan dengan metode injeksi. Penelitian yang dilakukan oleh Aswin (2016) menunjukan bahwa aplikasi dosis inokulan fungi Fusarium sp. berpengaruh nyata terhadap luas infeksi, perubahan warna kayu dan tingkat wangi dalam pembentukan gaharu pada pohon karas (Aquilaria malaccensis).

Terbatasnya pengetahuan petani gaharu tentang inokulasi gaharu dan mahalnya inokulan merupakan faktor pembatas untuk produksi gaharu budidaya. Hal ini disebabkan pembuatan inokulan dari biakan murni yang membutuhkan keahlian dan biaya yang mahal. Bioinokulan merupakan inokulan gaharu yang dibuat dari bahanbahan alami yang mengandung mikroorganisme patogen, dan tidak membutuhkan pembiakan murni dalam proses pembuatannya. Penelitian ini bertujuan untuk mengidentifikasi jenis-jenis mikroorganisme dan konsentrasi bioinokulan yang tepat digunakan untuk menghasilkan kualitas gaharu yang baik serta mengetahui kualitas gaharu yang dihasilkan dengan menggunakan bioinokulan dari fermentasi batang pisang yang terkena penyakit layu fusarium.

\section{METODE}

\section{Perbanyakan Inokulan Fusarium sp.}

Isolat Fusarium sp. diperoleh dari Laboratorium Mikrobiologi FMIPA Universitas Tanjungpura, Pontianak. Perbanyakan isolat Fusarium sp. dilakukan dalam medium cair Potato Dextrose Broth (PDB).

\section{Pembuatan Bioinokulan}

Pembuatan bioinokulan diawali dengan pemilihan bahan utama yaitu batang pisang yang terkena penyakit layu Bagian batang tersebut dipotong menjadi ukuran kecil \pm 2 $\mathrm{cm}$ berbentuk dadu. Potongan batang pisang kemudian ditimbang \pm 350 gram dan dihancurkan dengan menggunakan blender. Akuades ditambahkan sebanyak $200 \mathrm{ml}$, kemudian disaring menggunakan kain serbet dan diperas hingga air pada ampas batang pisang habis. Air hasil perasan dimasukan ke dalam jerigen dan ditutup, kemudian disimpan selama tiga hari pada suhu ruang dan tidak terkena cahaya matahari langsung.

\section{Isolasi dan Identifikasi Mikroorganisme Pada Bioinokulan}

Isolasi jamur dilakukan menggunakan metode agar tuang dengan membuat seri pengenceran. Pengenceran dilakukan dari 1 $\mathrm{ml}$ bioinokulan ke dalam $9 \mathrm{ml}$ aquades 
hingga didapatkan pengenceran $10^{-3}-10^{-5}$, kemudian diambil masing-masing $1 \mathrm{ml}$ dari setiap pengenceran dan tuangkan pada media, penuangan dilakukan secara aseptis. Proses inkubasi dilakukan pada suhu ruang selama 5 sampai 7 hari. Setiap jamur yang tumbuh dimurnikan kembali pada media PDA dan diinkubasi selama 5-7 hari. Pengamatan dilakukan terhadap warna koloni, konidiofor dan spora yang dihasilkan (Lisdayania et al 2013). Selanjutnya jamur diidentifikasi menggunakan buku identifikasi jamur "Pengenalan Kapang Tropik Umum”, Gandjar et al. (1999).

\section{Inokulasi Bioinokulan}

Penelitian ini menggunakan 6 pohon penghasil gaharu (Aquilaria sp.) yang berumur kurang lebih 6 tahun. Pohon diberi lubang dengan menggunakan bor engkol. Kedalaman lubang bor $\pm \frac{1}{3}$ diameter pohon, jarak antara lubang pertama dan tanah sejauh $30 \mathrm{~cm}$, jarak antar lubang secara vertikal $50 \mathrm{~cm}$. Penelitian ini menggunakan enam perlakuan dalam pemberian konsentrsi yaitu kontrol (-) (aquades $150 \mathrm{ml}$ ), kontrol (+) (Fusarium sp. $2 \mathrm{ml}$ ), $100 \mathrm{ml}$ bioinokulan, $120 \mathrm{ml}$ bioinokulan, $140 \mathrm{ml}$ bioinokulan dan $160 \mathrm{ml}$ bioinokulan. Masing-masing konsentrasi diinokulasikan pada pohon yang berbeda, dimana setiap pohon dibuat 5 lubang untuk memasukan inokulan yang ada dengan metode infus.

\section{Pembersihan Gaharu dan Uji Organoleptik Gaharu}

Setelah 4 bulan masing-masing pohon ditebang dan dilakukan carving atau proses pembersihan gaharu dari serat kayu, untuk melihat hasil inokulasi gubal gaharu yang terbentuk. Gubal gaharu dari masing-masing perlakuan ditimbang dan dilakukan pengamatan tingkat warna dengan menggunakan tabel warna, serta aroma dengan cara membakar gaharu yang terbentuk pada setiap perlakuan. Pengamatan wangi gaharu dilakukan melalui uji organoleptik yang dinyatakan dengan rataan skor dari 10 panelis yang sudah memiliki pengalaman dalam dunia gaharu.
Pengujian organoleptik merupakan pengujian yang didasarkan pada proses pengindraan. Skala skor wangi adalah $0=$ tidak wangi, 1 = kurang wangi, 2 = wangi, 3 = wangi sekali, dimana nilai interval $(0$ $0,5)$ tidak wangi, $(0,5-1,5)$ kurang wangi, $(1,5$ - 2,5) wangi, (2,5 - 3) wangi sekali (Wahyuningtias 2010).

\section{Penentuan Persentase Rendemen Ekstrak Gaharu}

Sampel kayu gaharu yang di ekstrak dihaluskan menjadi serbuk. Sebanyak $5 \mathrm{~g}$ serbuk gaharu dari setiap sampel diekstraksi dengan teknik sokletasi. Ekstraksi dilakukan dengan pelarut aseton dan metanol, masingmasing sebanyak $75 \mathrm{~mL}$. Ekstraksi dilakukan selama 3 jam atau hingga ekstrak di tabung sudah tidak berwarna, labu alas bulat dipanaskan dengan bantuan penangas air pada suhu $\pm 100^{\circ} \mathrm{C}$. Hasil ekstraksi selanjutnya dipekatkan dengan bantuan rotary evaporator. Ekstrak pekat berwarna cokelat kehitaman ditimbang untuk mengetahui rendemen resin gaharu, Rendemen dapat ditentukan dengan rumus berikut (Pasaribu et al 2013):

Rendemen resin $(\%)=\frac{\mathrm{A}}{\mathrm{B}} \times 100 \%$

keterangan :

$\mathrm{A}=$ Berat resin hasil ekstraksi

$\mathrm{B}=$ Berat serbuk gaharu sebelum diekstraksi

\section{Uji Fitokimia}

Uji fitokimia pada penelitian ini meliputi uji alkaloid, steroid, terpenoid, flavonoid, saponin, tanin dan fenol (Syafitri et al. 2014).

\section{Analisis Data}

Penelitian ini menggunakan teknik analisis deskriptif. Data disajikan dalam bentuk tabel tentang rerata berat kayu gaharu, kualitas warna, aroma dan uji fitokimia, serta persentase rendemen ekstrak gaharu pada Aquilaria sp. (Pasaribu et al 2013).

\section{HASIL DAN PEMBAHASAN}

Hasil penelitian yang telah dilakukan diperoleh tiga kelompok mikroorganisme 
yang diisolasi dari bioinokulan fermentasi batang pisang yang terkena penyakit layu fusarium, yaitu dari kelompok genus Aspergillus, Fusarium dan Saccharomyces (Gambar 1-3).

Hasil penelitian yang telah dilakukan diperoleh tiga kelompok genus jamur yang diisolasi dari bioinokulan fermentasi batang pisang yang terkena penyakit layu fusarium, yaitu dari kelompok genus Aspergillus dan Fusarium yang tergolong kelompok jamur multiseluler, serta Saccharomyces dari kelompok jamur uniseluler. Bioinokulan mengandung tiga kelompok genus jamur yang berbeda. Hal ini memungkinkan adanya sinergisme atau kerja sama di antara ketiga kelompok jamur tersebut sehingga proses infeksi terhadap pohon penghasil gaharu menjadi lebih baik dibandingkan dengan inokulan dari biakan jamur tunggal. Menurut Subowo (2010) jamur Aspergillus dan Fusarium dapat membentuk gubal gaharu, tetapi memiliki hasil yang berbeda dimana jamur Fusarium memiliki hasil yang lebih baik dalam pembentukan gaharu dibandingkan jamur Aspergillus. Hasil penelitian Mega dan Phabiola (2010) menyatakan campuran dua mikroorganisme yaitu jamur Fusarium solani dan Rhizopus sp. menghasilkan mutu gaharu yang lebih baik dibandingkan perlakuan jamur tunggal.

Berdasarkan Tabel 1 rerata berat kayu gaharu yang dihasilkan beragam. Hasil inokulasi menggunakan bioinokulan dengan konsentrasi $140 \mathrm{ml}$ memiliki berat gaharu rata-rata tertinggi yaitu 40 gram, berat ratarata terkecil didapatkan dari hasil inokulasi gaharu dengan menggunakan Fusarium sp. (kontrol +) dengan rata-rata berat 2,6 gram, sedangkan untuk perlakuan dengan menggunakan akuades (kontrol -) tidak menghasilkan gaharu. Menurut Vantompan et al. (2015) akumulasi fitoaleksin atau metabolik sekunder akibat infeksi hifa-hifa jamur patogen menyebabkan adanya kumpulan resin yang bertumpuk di sekitar lubang perlukaan. Kumpulan resin inilah yang membuat gaharu terbentuk dan memberikan bobot pada gaharu. Semakin luas dan banyak fitoaleksin yang terakumulasi maka akan semakin berat gaharu yang terbentuk.

Perbedaan konsentrasi bioinokulan yang diberikan menghasilkan rerata berat kayu gaharu yang bervariasi. Konsentrasi bioinokulan yang rendah menghasilkan gaharu dengan retata berat gaharu yang kecil. Hal ini disebabkan pohon penghasil gaharu mampu memberikan perlawanan terhadap infeksi dari mikroorganisme yang terkandung di dalam bioinokulan, sehingga gaharu yang terbentuk sedikit. Namun pada perlakuan konsentrasi yang terlalu tinggi dapat menyebabkan terganggunya fungsifungsi fisiologis dari tumbuhan penghasil gaharu sehingga dapat menyebabkan pohon menjadi lapuk bahkan mati. Proses fisiologis yang terganggu menyebabkan gaharu yang terbentuk kurang baik dan berat gaharu yang dihasilkan menjadi rendah (Aswin 2016).

Hasil penelitian pada Tabel 2 menunjukan bahwa warna gaharu yang dihasilkan berbeda-beda pada setiap perlakuan. Secara kualitatif warna gubal yang dihasilkan dari perlakuan inokulasi dengan beberapa konsentrasi bioinokulan bervariasi yaitu krem, abu-abu kecokelatan, kuning kecokelatan dan cokelat. Hal ini berhubungan erat dengan kandungan resin dan aroma. Perlakuan bioinokulan $140 \mathrm{ml}$ dan $120 \mathrm{ml}$ menghasilkan kayu gaharu berwarna cokelat. Gaharu dari perlakuan Fusarium sp. atau kontrol (+) memiliki warna kuning kecokelatan dan gaharu dari perlakukan bioinokulan $100 \mathrm{ml}$ memiliki warna abu-abu kecokelatan, sedangkan dari perlakukan bioinokulan $160 \mathrm{ml}$ dengan warna krem. Hal ini menunjukan bahwa perlakuan bioinokulan konsentrasi $120 \mathrm{ml}$ dan $140 \mathrm{ml}$ memberikan hasil yang terbaik dibandingkan perlakuan lainnya. 


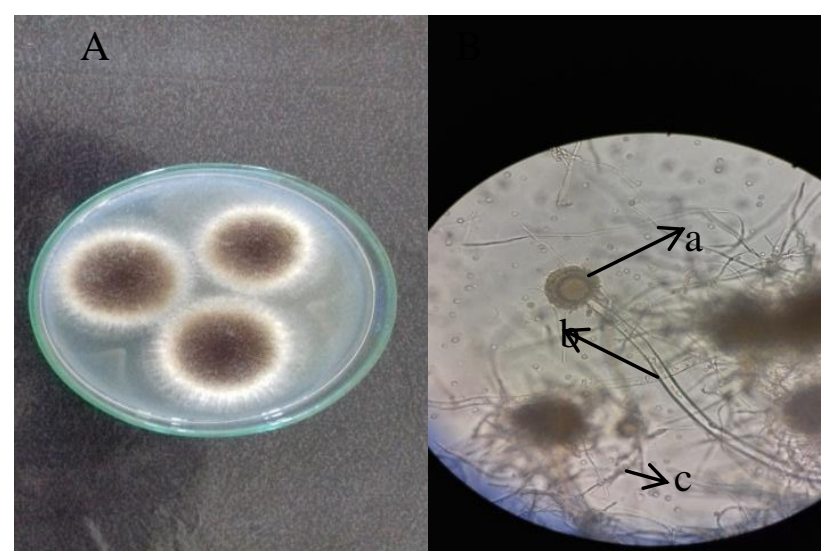

Gambar 1: A .Koloni Aspergillus sp.

B. Morfologi Aspergillus sp. secara mikroskopis

a. Konidia, b. Konidiafor, c. Hifa, Perbesaran 10 x 10

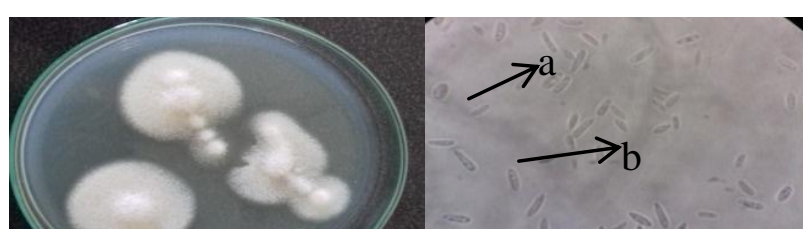

Gambar 2: A. Koloni Fusarium sp.

B. Morfologi Fusarium sp. secara mikroskopis,

a. Makrokonidia, b. Mikrokonidia, Perbesaran 10 x 40

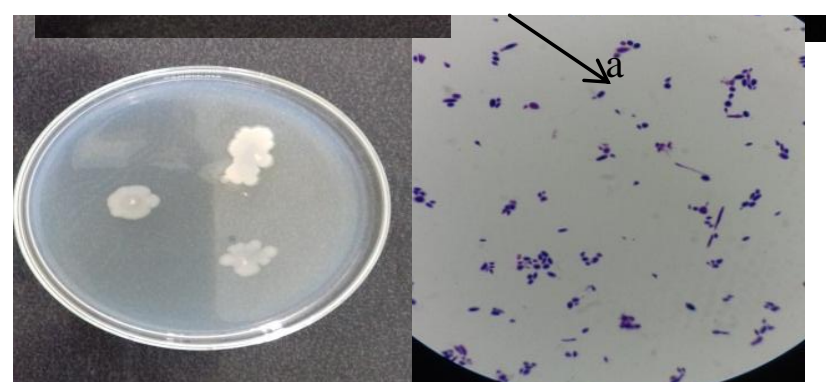

Gambar 3: A. Koloni Saccharomyces sp.

B. Morfologi Saccharomyces sp. secara mikroskopis,

a. Sel tunas (budding sel), Perbesaran 10 x 40

Tabel 1 Rerata berat kayu gaharu setelah 4 bulan inokulasi

\begin{tabular}{cc}
\hline Perlakuan $(\mathrm{ml})$ & rata-rata berat (gram) \\
\hline Akuades (-) 150 & - \\
Fusarium (+) 2 & 2,6 \\
Bioinokulan 100 & 12,8 \\
Bioinokulan 120 & 22,6 \\
Bioinokulan 140 & 40 \\
Bioinokulan 160 & 19 \\
\hline
\end{tabular}

Tabel 2 Kualitas warna kayu gaharu

\begin{tabular}{cc}
\hline Perlakuan (ml) & Warna \\
\hline Akuades (-) 150 & - \\
Fusarium (+) 2 & Kuning kecokelatan \\
Bioinokulan 100 & Abu-abu kecokelatan \\
Bioinokulan 120 & Cokelat \\
Bioinokulan 140 & Cokelat \\
Bioinokulan 160 & Krem \\
\hline
\end{tabular}


Tabel 3 Kualitas aroma kayu gaharu

\begin{tabular}{lcc}
\hline Perlakuan (ml) & Rata-rata skor & Kualitas aroma \\
\hline Akuades (-) 150 & - & - \\
Fusarium (+) 2 & 1,2 & Kurang wangi \\
Bioinokulan 100 & 1,7 & Wangi \\
Bioinokulan 120 & 2,3 & Wangi \\
Bioinokulan 140 & 2,7 & Wangi sekali \\
Bioinokulan 160 & 1,2 & Kurang wangi \\
\hline
\end{tabular}

Keterangan: Skor 0 - 0,5 (tidak wangi), 0,5 - 1,5 (kurang wangi), 1,5-2,5 (wangi), 2,5 - 3 (wangi sekali).

Tabel 4 Persentase rendemen resin gaharu pada pelarut yang berbeda

\begin{tabular}{cccc}
\hline Pelarut & Sampel & Berat resin (gram) & Rendamen resin (\%) \\
\hline Aseton & Fusarium (+) $2 \mathrm{ml}$ & 0,5 & $10 \%$ \\
& Bioinokulan $100 \mathrm{ml}$ & 0,41 & $8,2 \%$ \\
& Bioinokulan $120 \mathrm{ml}$ & 1,14 & $22,8 \%$ \\
& Bioinokulan $140 \mathrm{ml}$ & 1,73 & $34,6 \%$ \\
& Bioinokulan $160 \mathrm{ml}$ & 0,55 & $11 \%$ \\
Metanol & Fusarium (+) $2 \mathrm{ml}$ & 0,93 & $18,6 \%$ \\
& Bioinokulan $100 \mathrm{ml}$ & 1,17 & $23,4 \%$ \\
& Bioinokulan $120 \mathrm{ml}$ & 1,36 & $27,2 \%$ \\
& Bioinokulan $140 \mathrm{ml}$ & 1,35 & $27 \%$ \\
& Bioinokulan $160 \mathrm{ml}$ & 0,5 & $10 \%$ \\
\hline
\end{tabular}

Tabel 5 Uji fitokimia

\begin{tabular}{|c|c|c|c|c|c|c|c|c|}
\hline Pelarut & Sampel & Alkaloid & Steroid & Terpenoid & Flavonoid & Saponin & Tanin & Fenol \\
\hline \multirow[t]{5}{*}{ Aseton } & $\begin{array}{l}\text { Fusarium } \\
\text { (+) } 2 \mathrm{ml}\end{array}$ & - & - & + & + & - & - & + \\
\hline & $\begin{array}{l}\text { Bioinokula } \\
\text { n } 100 \mathrm{ml}\end{array}$ & - & - & + & + & - & - & + \\
\hline & $\begin{array}{l}\text { Bioinokula } \\
\text { n } 120 \mathrm{ml}\end{array}$ & - & - & + & + & - & - & - \\
\hline & $\begin{array}{l}\text { Bioinokula } \\
\text { n } 140 \mathrm{ml}\end{array}$ & + & - & + & + & - & - & + \\
\hline & $\begin{array}{l}\text { Bioinokula } \\
\text { n } 160 \mathrm{ml}\end{array}$ & - & - & - & + & - & - & + \\
\hline \multirow[t]{5}{*}{ Metanol } & $\begin{array}{l}\text { Fusarium } \\
\text { (+) } 2 \mathrm{ml}\end{array}$ & - & - & - & + & - & + & ++ \\
\hline & $\begin{array}{l}\text { Bioinokula } \\
\text { n } 100 \mathrm{ml}\end{array}$ & - & - & - & + & - & + & ++ \\
\hline & $\begin{array}{l}\text { Bioinokula } \\
\text { n } 120 \mathrm{ml}\end{array}$ & + & - & + & + & - & + & ++ \\
\hline & $\begin{array}{l}\text { Bioinokula } \\
\text { n } 140 \mathrm{ml}\end{array}$ & + & - & + & + & - & + & + \\
\hline & $\begin{array}{l}\text { Bioinokula } \\
\text { n } 160 \mathrm{ml}\end{array}$ & - & - & + & - & - & + & + \\
\hline
\end{tabular}

Keterangan : - : tidak mengandung senyawa

+ : mengandung senyawa

++ : banyak mengandung senyawa

Menurut Santoso et al. (2007) bagian pohon Aquilaria malaccensis yang terinfeksi mengeluarkan senyawa oleoresin dari jenis sesquiterpen yang menyebabkan jaringan kayu berwarna coklat sampai kehitaman. Semakin banyak kandungan resin gaharu yang terdeposit dalam jaringan kayu maka akan semakin gelap pula warna kayu yang di timbulkannya dan semakin baik kualitas gaharu tersebut.

Hasil penelitian pada Tabel 3 menunjukan bahwa kualitas aroma terbaik 
dihasilkan pada perlakuan bioinokulan 140 $\mathrm{ml}$ yaitu wangi sekali. Perlakuan bioinokulan $160 \mathrm{ml}$ memberikan hasil yang terendah yaitu kurang wangi. Aroma wangi gaharu di pengaruhi oleh jumlah resin yang merupakan metabolit sekunder yang dihasilkan tanaman gaharu sebagai respon terhadap infeksi jamur patogen. Hasil ini sesuai dengan hasil uji fitokimia yang dilakukan dimana pada sampel dari perlakuan bioinoukulan $140 \mathrm{ml}$ mengandung paling banyak senyawa metabolit sekunder terutama senyawa terpenoid, sedangkan perlakuan $160 \mathrm{ml}$ mengandung paling sedikit senyawa metabolit sekunder (Tabel 4 dan 5). Menurut Nakanishi et al. (1984), senyawa wangi yang utama pada gaharu adalah kelompok turunan senyawa sesquiterpen (Terpenoid) dan kromon feniletil. Kandungan sesquiterpen yang bervariasi akan menentukan kualitas gaharu. Selain sesquiterpen, gaharu asal Indonesia juga mengandung komponen pokok minyak gaharu berupa kromon. Kromon inilah yang menyebabkan aroma harum dari gaharu bila dibakar (Subowo 2010).

Hasil Tabel 4 menunjukan bahwa sampel gaharu pada perlakuan konsentrai $140 \mathrm{ml}$ memiliki kandungan rendamen resin tertinggi sedangkan sampel gaharu dari konsentrasi $160 \mathrm{ml}$ memiliki kandungan rendamen resin terendah. Hal ini sesuai dengan hasil dari beberapa penentuan kualitas gaharu sebelumnya seperti dari berat, warna, dan aroma gaharu dimana sampel gaharu dari konsentrasi $140 \mathrm{ml}$ memiliki hasil yang terbaik dari konsentrasi lainnya, sedangkan sampel gaharu dari konsentrasi $160 \mathrm{ml}$ memiliki hasil yang rendah. Rendemen resin antara pelarut metanol dan aseton tidak menunjukan perbedaan yang nyata, akan tetapi terlihat kecenderungan rendemen resin pada pelarut metanol lebih tinggi dibandingkan pelarut aseton. Hal ini disebabkan oleh pelarut metanol memiliki sifat yang dapat melarutkan hampir semua komponen baik yang bersifat polar, semi polar maupun non polar (Pasaribu et al 2013).
Dari ke empat standar penentuan mutu gaharu seperti berat, warna, aroma dan rendamen resin gaharu dapat disimpulkan bahwa gaharu dari perlakuan konsentrasi $140 \mathrm{ml}$ memiliki hasil yang terbaik dibandingkan perlakuan lainnya. Berdasarkan warna dan aroma gaharu yang dihasilkan dari perlakuan konsentrasi bioinokulan $120 \mathrm{ml}$ dan $140 \mathrm{ml}$ ini dapat di kategorikan kedalam kelas kemedangan, sedangkan perlakuan kontrol (+) Fusarium sp., bioinokulan $100 \mathrm{ml}$ dan $160 \mathrm{ml}$ dapat dikategorikan ke dalam kelas kemedangan muda.

\section{Kesimpulan}

Berdasarkan hasil penelitian dapat disimpulkan terdapat tiga jenis mikroorganisme yang diisolasi dari bioinokulan fermentasi batang pisang yang terkena penyakit layu fusarium, yaitu dari kelompok genus Aspergillus, Fusarium dan Saccharomyces. Konsentrasi bioinokulan $140 \mathrm{ml}$ memberikan hasil yang terbaik baik dari bobot kayu, warna, aroma maupun dari kadar resin gaharu yang dihasilkan. Kualitas gaharu yang dihasilkan menggunakan bioinokulan selama 4 bulan masa inokulasi menghasilkan mutu gaharu kelas kemedangan.

\section{DAFTAR PUSTAKA}

Aswin (2016) Inokulasi Fusarium sp. Pada Pohon Karas (aquilaria malaccencis lamk.) Terhadap Pembentukan Gaharu, Jurnal Kehutanan Vol.11, No.

Gandjar IRA, Samson KVT, Veumeuleum A, Oetari dan Santoso (1999)

Pengenalan Kapang Tropik Umum, Yayasan Obor Indonesia: Jakarta.

Lisdayania, Nelly A, Siregar EBM (2013)

Reisolasi dan Identifikasi Fungi pada Batang Gaharu (Aquilaria malaccencis Lamk.) Hasil Inokulasi, Program Studi Kehutanan, Fakultas Pertanian, Universitas Sumatera Utara

Mega IM dan Phabiola TA (2010) Isolasi Jamur Pembentuk Gubal Gaharu Pada Tanaman Gyrinops Verstegii di 
Kecamatan Pupuan Kabupaten Tabanan, Agritrop Vol. 29, No. 4, Hal. 189-198.

Nakanishi T, Etsuko Y, Yoneda K, Nagashima T, Kawasaki I, Yoshida T, Mori H, dan Miura I (1984) Three fragrant Sesquiterpenes of Agarwood, Phytochemistry 23 : 2066-2067.

Pasaribu G, Totok K, Waluyo, Gustan Pari (2013) Analisis Komponen Kimia Beberapa Kualitas Gaharu Dengan Kromatografi Gas Spektrometri Massa, Jurnal Penelitian Hasil Hutan Vol. 31 No. 3 hal: 181-185.

Purnomo E, dan Turjaman M (2011) The environmental of characteristics of Kandangan site for gaharu plantation projects. Proceeding of gaharu workshop: "Development of gaharu production technology a forest community based empowerment, ITTO PD425/06 Rev.1 (I). Bogor. 95-104.

Santoso E, Irianto RSB, Sitepu IR, Turjaman M (2011a) Better inoculation engineering techniques, Technical Report 2, ITTO PD425/06 Rev.1. R\&D Center for Forest Conservation and Rehabilitation. Bogor.

Santoso E, Agustini L, Sitepu IR, Turjaman M (2007) Efektivitas Pembentukan Gaharu Dan Komposisi Senyawa Resin Gaharu Pada Aquilaria Spp, Jurnal Penelitioan Hutan Dan Konservasi Alam,Vol. IV No. 6 : 543-551.
Santoso E, Pratiwi, Purnomo E, Irianto RSB, Wiyono B, Novriyanto E, Turjama M (2011b) Selection pathogens for eaglewood (gaharu) inoculation. Technical Report 3. ITTO PD425/06 Rev.1. R\&D Center for Forest Conservation and Rehabilitation, Bogor

Siran SA, dan Turjaman M (2010) Pengembangan teknologi gaharu berbasis pemberdayaan masyarakat, Pusat Penelitian dan Pengembangan Hutan dan Konservasi Alam, Bogor.

Subowo YB (2010) Jamur Pembentuk Gaharu Sebagai Penjaga Kelangsungan Hidup Tanaman Gaharu (Aquilaria sp.), Jurnal Teknologi Lingkungan, Vol 11(2): $167-173$.

Syafitri NE, Maria B, Syamsul F (2014) Kandungan Fitokimia, Total Fenol, dan Total Flavonoid Ekstrak Buah Harendong (Melastoma affine D.Don) Jurnal Current Biochemistry, Volume 1 (3): $105-115$

Vantompan DPW, Savante A, Wibowo AM (2015) Perbandingan Inokulan Fusarium sp. Menggunakan Metode Infus dan Injeksi Untuk Mendapatkan Gaharu Pada Pohon Aquilaria malaccensis, Program Studi Kimia, Fakultas MIPA, Universitas Tanjungpura.

Wahyuningtias D (2010) Uji Organoleptik Hasil Jadi Kue Menggunakan Bahan Non Instant Dan Instant, Jurnal Binus Business Review. Vol.1 No.1: 116-125. 